research institutes is being carried out by a division of 14 staff within the Administrative Inspection Bureau. At eight to ten evaluations per year, it is clearly going to take them some time to complete the first round of appraisals. Interestingly, there is no requirement for the inspectors to have a science degree. They operate by collecting written material from the institute, and then conducting a site visit, which is followed by hearings with external experts or users of the institute. It is already clear that they are willing to recommend closure of programmes of research.

As well as the infrequent attention of the inspectors, institutes and programmes are increasingly subject to review by their parent agency. The Japanese have recognized the need to build up the skills needed for this task; interestingly, they differ from Western countries in making little use of external evaluators from consultancy firms or research institutes. They also differ from at least some Western countries in having no hang-ups about the role of the state in the support of industrially relevant research and development. Projects in the Agency of Industrial Science and Technology have a planned duration of ten years; they are chosen in part because they are expected to have an industrial impact yet cannot be undertaken by private firms because of the risk involved; and the Japanese do not, as in Britain, apply an 'additionality' test (which constrains the state to fund only work that would not otherwise have been undertaken by firms), but instead use government funds to coordinate and target research of the highest priority that would in any case be carried out by companies.

Increasingly, Japanese projects have evaluation criteria built into them from the outset. In this respect they follow standard planning practice of identifying goals and specifying how one will tell whether they are being achieved. Considerable work goes into ex ante evaluation of the potential importance of candidate research programmes. Special efforts have been made in recent years to introduce effective mid-term reviews, which enable programmes to be changed and resources concentrated on the more promising areas in the light of experience gained earlier on. Quantitative performance indicators are used, particularly patents and publications, and Irvine detected some evidence that the Japanese government is tempted by evaluation techniques that lend themselves to simple quantification. However, calculations of rates of return are attempted only rarely for government-funded programmes. Instead, emphasis is put upon whether or not projects are achieving previously defined technical and other strategic goals (which might include building a national capability in a particular area of technology). Care is always taken to discuss the results of the appraisal with the appraisees, not least because of a desire to generate a commitment among researchers themselves to the idea that assessment will not only improve efficiency but is also in their interests.

There is a danger that the evaluator may inherit the mantle of Oscar Wilde's cynic, who knew the price of everything and the value of nothing. To gain the benefits of evaluation while avoiding the pitfalls is a task of growing importance, to which this book makes a valuable contribution.

Philip Gummett is Senior Lecturer in the Department of Science and Technology Policy, University of Manchester, Manchester MI3 9PL, UK

\section{Rhine maidens}

\section{Steve Blinkhorn}

Forbidden Knowledge: The Paranormal Paradox. By Bob Couttie. Lutterworth: 1988. Pp.155. £9.95.

THE lunar branch of marine biology is not a thriving field of research. Before 1969 it might have been possible to hope for a renaissance, but it is to the eternal credit of science that no one any more thinks that there are mermaids on the Moon - not even very small mermaids.

Sadly, the lesson has not been learned by parapsychologists. In the nineteenth century, belief in a parallel reality, a different order of causality, led to reports of paranormal manifestations on a scale and intensity which demanded attention. Tables flying through the air unaided by forces known to the heirs of Newton; ectoplasm in grocers' quantities; thought transference, spirit manifestations and hauntings of an intensity commensurate with the existence of an independent élan vital.

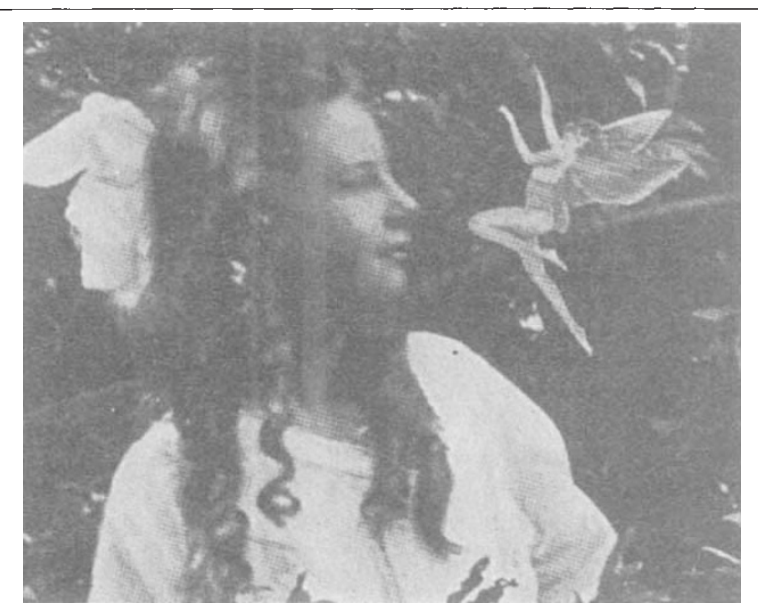

Fairy tales - pictures of the Cottingley fairies, published in Strand Magazine in 1917, caused a storm of controversy. Only many years later did the girls admit the pictures were faked. The picture is taken from The Reality of the Paranormal by Arthur Ellison, published by Harrap price $\$ 12.95$.
Curiously, the paranormal has become decidedly less spectacular. At best these days we have the spoon-bending antics of Yuri Geller, and laboratory effects which strain for statistical significance by dint of mind-numbing repetition of trials. Parapsychology has retreated to claiming, in effect, that on the Moon are mermaids of microscopic proportions.

Forbidden Knowledge examines the current state of parapsychology from the point of view of an experienced practitioner of long-distance magic. Here is a book that deserved to have been written at greater length. As it is, it effectively dishes parapsychology, to the extent of providing a cookbook of methods for replicating spoon-bending and spirit-communicating stunts. But Couttie's prose style stumbles over itself in haste, and the argument suffers from superficial reference to research rather than detailed discussion. Having made a special study of the field, the author's talent for communicating his knowledge is stretched.

So, as a book Forbidden Knowledge fails to satisfy. Nonetheless, it is welcome. The fundamental flaw in popular accounts favourable to the paranormal is accurately identified: only positive results find ready publication. One could add that selective publication subverts all classical hypothesis-testing on a statistical model and that even the best-designed experiments can admit of more than one alternative hypothesis given rejection of the null hypothesis. Hypotheses involving extra-sensory perception, thought transference and the like are difficult to frame in the first place, and the usual statement that a set of results could only have happened by chance at some extreme level of improbability glides over the range of uncontrolled factors which could provide a mundane explanation. Close inspection typically reveals just such uncontrolled factors, and Couttie neatly disposes of a number of highly publicized instances of paranormal phenomena which were greeted with breathless enthusiasm, but turn out to have been examples of the conjuror's art. So much for the impressive significance levels frequently cited in ESP laboratory reports

However, if you want to find out how to bend spoons à la Geller, summon up spirits à la Doris Stokes or just read the truth about some past cases of haunting, Forbidden Knowledge is in a class of its own. Lunar mermaids will hate it - but that's their problem.

Steve Blinkhorn is Managing Director of PRD Ltd, 36-38 London Road, St Albans ALI ING, UK 